\title{
Civilisations
}

Revue internationale d'anthropologie et de sciences

humaines

$48 \mid 2001$

La question de l'islam et de l'Etat à l'aube du XXIe siècle

\section{Avertissement et remerciements}

\section{(2) OpenEdition \\ Journals}

\section{Édition électronique}

URL : http://journals.openedition.org/civilisations/3451

DOI : 10.4000/civilisations.3451

ISSN : 2032-0442

\section{Éditeur}

Institut de sociologie de l'Université Libre de Bruxelles

\section{Édition imprimée}

Date de publication : 31 août 2001

ISSN : 0009-8140

Référence électronique

"Avertissement et remerciements », Civilisations [En ligne], 48 | 2001, mis en ligne le 30 avril 2014 consulté le 22 septembre 2020. URL : http://journals.openedition.org/civilisations/3451 ; DOI : https:// doi.org/10.4000/civilisations.3451

Ce document a été généré automatiquement le 22 septembre 2020.

(C) Tous droits réservés 


\section{Avertissement et remerciements}

1 Les textes regroupés dans cet ouvrage ont été présentés à un colloque sur l'Islam et l'État qui a eu lieu en mai 1999 à l'Institut de Sociologie de l'Université Libre de Bruxelles. La pertinence et l'objet essentiel de chacun d'entre-eux demeurent inchangés à l'heure de la publication. Néanmoins des aménagements mineurs ont été effectués.

2 Les éditeurs ont en outre unifié l'écriture pour une plus grande facilité de lecture et les auteurs ne sont donc pas responsables de ces aménagements.

3 Les éditeurs tiennent à remercier chaleureusement les auteurs pour leurs contributions, Olivier Carré, Robert Anciaux, Muhammad Reza Djalili, Brigitte Piquard, , Ahmed Benani, Mohamed El Battiui, Jean-François Legrain, Jocelyne Cesari, Vincent Geisser, Yassine Didier Beyens, John Eade et Gema Martin-Munoz.

4 Les éditeurs remercient également Madame Anne-Marie Desmarlières qui a assuré la présentation et la mise en page de cet ensemble, ainsi que le CGRI, le Ministère de l'Education, de la Recherche et de la Formation, le FNRS qui ont soutenu l'organisation de ce colloque et permis la publication des actes. 